SIGNALIING molecules are thought to play a significant role in determining the fate of neural crest progenitor cells. The human sympathetic chain was identified at 6.5 , $7.5,8.2,10.2$ and 11.4 postconception (PC) weeks demonstrating low affinity nerve growth factor (NGF) receptors, and was processed for tissue culture. In the presence of epidermal growth factor (EGF), floating spheres of proliferating progenitor cells were developed in vitro. In the absence of EGF progenitor cells differentiated into tyrosine hydroxylase (TH)-immunoreactive neuronal and TH-negative flat cells. NGF treatment significantly increased neurite outgrowth and survival of TH-immunoreactive cells. The multipotent cells we isolated differ from previously reported sympathoadrenal progenitors in that they give rise to $\mathrm{TH}$ immunoreactive neurones precociously sensitive to NGF.

Key words: Neural crest; Sympathetic neurones; Progenitor cell; Nerve growth factor (NGF); Epidermal growth factor (EGF); Tissue culture

\section{NGF-response of EGF- dependent progenitor cells obtained from human sympathetic ganglia}

\author{
Vincenzo Silani, $\mathrm{CA}$ \\ Gian Domenico Borasio,' Feng C. Zhou, ${ }^{2}$ \\ Simona Bernasconi, Antonio Pizzuti, \\ Alberto Sampietro and \\ Guglielmo Scarlato
}

Institute of Neurology, 'Dino Ferrari' Centre, University of Milan Medical School, Via F. Sforza 35, I-20122 Milan, Italy; ${ }^{1}$ Neurologische Klinik der Ludwig-Maximilians-Universität München, Klinikum Grosshadern, D-81366 München, Germany; ${ }^{2}$ Indiana University School of Medicine, Department of Anatomy, Indianapolis, IN, USA

"A Corresponding Author

\section{Introduction}

Sympathoadrenal (SA) lineage is a neural crest derivative that has been investigated in detail.' It differentiates to form sympathetic neurones, the adrenal gland primordia (then chromaffin cells) and the small intensely fluorescent (SIF) cells. A peculiar feature of these cell types is their ability to be phenotypically interconverted by specific environmental signals. ${ }^{2}$ The plasticity is supposed to reflect the development from a common embryonic progenitor cell..$^{3-5} \mathrm{NGF}$, along with glucosteroids, is one of the most important environmental determinants of the cell fate in vivo. ${ }^{4,6-8}$ Recently, investigators were able to establish a v-mycimmortalized SA progenitor cell line $e^{9}$ and isolate a common stem cell for neurones and glia from the mammalian neural crest. ${ }^{10}$

The purpose of the present study was to obtain EGF-responsive progenitor cells from the human developing sympathetic autonomic chain, according to the experimental procedure described for the murine central nervous system by Reynolds and Weiss." Specific features such as TH expression and early NGF response with neurite outgrowth and increased survival, were used as specific functional assays for the neural derivatives obtained from the EGF-dependent progenitor cells we were able to isolate. ${ }^{12}$

\section{Material and Methods}

Human embryonic tissues were obtained from patients undergoing therapeutic abortions according to the current Italian laws. The Institutional Ethical Committee approved the experiments and informed consent from the patients was obtained.

Staging of human embryos: The age of the embryos was determined by preoperative ultrasound scanning, which allowed a good estimation of embryonic crownrump length (CRL) and staging before the embryo was obtained by suction abortion. Other distinguished features, such as foot length, hand morphology, last menstrual period (LMP) and staging of development according to the Carnegie Collection criteria ${ }^{13}$ were recorded for embryos younger than PC week 8. For PC age $>8$ weeks, donors were staged by LMP and CRL as determined ultrasonically in utero. ${ }^{14}$ Sonographic measurements were able to predict the gestational age from 8.0 to 12.6 weeks with an accuracy of \pm 4 days. ${ }^{15,16}$ The age of the embryos was estimated by a 
combination of the above features and expressed as a PC week. PC weeks and days were derived from CRL values as previously reported. ${ }^{\text {is }}$

Localization of the ganglia in the sympathetic autonomic chain by fluorescence microscopic detection of the low affinity NGF receptors ( $p^{\text {s.NGFR }}$ ): Specimens were immediately immersion-fixed for $12-24 \mathrm{~h}$ in $4 \%$ paraformaldehyde, rinsed, cryoprotected in increasing sucrose concentration (7-15\%), and frozen in ethanolliquid nitrogen. Spinal cord, dorsal root ganglia and sympathetic ganglia were shown in the same specimen. Frozen $16 \mu \mathrm{m}$ horizontal sections were cryostat sectioned (Top Cryo E, Pabisch) and treated for immunohistochemical studies. For the low affinity $\mathrm{p}^{\text {7s-NGFR }}$ localization, two specific monoclonal antibodies anti-p $\mathrm{p}^{75-N G F R}$ (from clones ME 20.4 (Amersham) and 8211 (Boehringer Mannheim, IN) respectively) were used. Sections were washed with PBS, overlaid with mouse anti-p ${ }^{\text {75-NGFR }}$ diluted 1:50 in PBS overnight at $4^{\circ} \mathrm{C}$, washed with PBS, added with FITC anti-mouse $\operatorname{IgG}\left(1: 40\right.$ in PBS) for $1 \mathrm{~h}$ at $4^{\circ} \mathrm{C}$, and then washed three times with $\mathrm{PBS}$ and mounted. Sections were examined on a Zeiss transmitted-light photomicroscope III equipped with an epi-fluorescence condenser.

EGF-dependent progenitor cell isolation in vitro: To obtain SA cells, specimens at PC week 6.5, 7.5, 8.2, 10.2 and 11.4 were collected in sterile Hank's balanced salt solution, $\mathrm{pH} 7.4$ (Gibco) and immediately processed for tissue culture. The SA system was isolated using a sterile technique, under an inverted microscope. After careful dissection of the nervous tissue from meninges, vessels and any other contaminants, sympathetic ganglia were isolated and immediately cut into pieces using scissors. Tissues were then added with Dulbecco's modified Eagle's medium and F12 nutrient $(1: 1, \mathrm{v} / \mathrm{v}$; Sigma) supplemented with antibiotics and glucose (5 $\mathrm{mg}^{-1}$ ). A defined hormone and salt mixture (defined supplements) that included insulin $\left(25 \mu \mathrm{g} \mathrm{ml}^{-1}\right)$, transferrin $\left(100 \mu \mathrm{g} \mathrm{ml}^{-1}\right)$ progesterone $(20 \mathrm{nM})$, putrescine $(60 \mu \mathrm{M})$, and selenium chloride $(30 \mathrm{nM})$ was used in place of serum. Trypsin (II, Sigma) at a low concentration $(0.08 \%, v / v)$ was used to facilitate cell dissociation. Tissues were incubated for $15-20 \mathrm{~min}$ at $36.5^{\circ} \mathrm{C}$ in $5.5 \% \mathrm{CO}_{2}$, before trypsin was removed. Dispersed cells were centrifuged $(500 \times g$ for $10 \mathrm{~min}$ ) for pellets and resuspended in DMEM/F12 and gently dissociated by trituration with Pasteur pipettes of progressively smaller bore size. Dispersed cells were then plated without any attachment factor. An average viable cell number of $4 \times 10^{4}$ was obtained from a single ganglion. Ten thousand cells were plated in a $16 \mathrm{~mm}$ dish in DMEM/F12 medium with defined supplements and $20 \mathrm{ng} \mathrm{ml}^{-1}$ human recombinant epidermal growth factor (EGF, Boehringer Mannheim, IN) in the absence of serum. After 8-10 days in vitro, floating cell clusters (spheres) were collected, centrifuged at $500 \times g$ for $10 \mathrm{~min}$, resuspended in EGF-free medium and then mechanically dissociated to single cells. Isolated EGFdependent progenitor cells were subcultured in the presence of EGF-DMEM/F12 with defined supplements to obtain second passage spheres (repeated passages). Spheres were subsequently dissociated to single cells and plated at a clonal density of $100 \pm 6$ cells on $35 \mathrm{~mm}$ Falcon dishes, pre-coated overnight with poly-L-lysine (mol wt $90000-120000,10 \mu \mathrm{g} \mathrm{ml}^{-1}$ in $0.15 \mathrm{M}$ sodium borate buffer, $\mathrm{pH} 8.4$ ). Cultures were incubated at $36.5^{\circ} \mathrm{C}$ in a humidified atmosphere of $5.5 \% \mathrm{CO}_{2}$. Every 2-3 days half of the medium was removed from each well and replaced with an equal volume of fesh medium (DMEM/F12) with defined supplements, in the absence of EGF.

NGF treatment of the progenitor cells and morphologi-

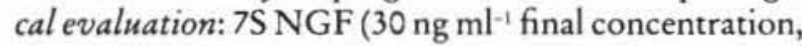
Sigma) was added to the cultures on the first in vitro day, $2 \mathrm{~h}$ after plating. Cells were observed every $4-6 \mathrm{~h}$ using an inverted microscope for the first $24 \mathrm{~h}$. Cell counting was performed after 6 and 12 days in vitro using an inverted microscope with phase contrast objectives and a high numerical opening, magnification $\times 320$. Selected areas of each well (approximately $7 \%$ of the $35 \mathrm{~mm}$ well surface) were scanned for the presence of phase-bright cells with/without neurites at 6 and 12 days in vitro to determine both survival rates (number of neurones which have survived in the presence/ absence of NGF) and the percentage of neurones with neurites (processes more than a cell diameter in length). Approximately 500 viable EGF-dependent progenitor cells (clonal lines) were monitored between $\mathrm{O}$ and 12 days in vitro both in NGF-treated and control cultures.

Immunocytochemistry of progenitor cells in culture: Progenitor cells were fixed with $4 \%$ paraformaldehyde for $1 \mathrm{~h}$ and permeabilized with $0.1 \%$ Triton X-100 for $30 \mathrm{~min}$. After adding goat serum, cultures were incubated with an anti-TH monoclonal or polyclonal antibody (monoclonal from Incstar and polyclonal from Eugene Tech, 1:100 and 1:500 dilution, respectively) and, subsequently, with goat FITC conjugated antimouse IgG (1:100) (bioYeda). Progenitor cells were fixed both after 0 days in vitro, immediately after attachment (2-3 h), and at 6 days in vitro.

\section{Results}

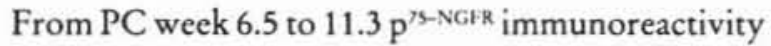
was localized in the ganglia of the sympathetic autonomic chain symmetrically positioned in front of the vertebrae. Three anatomical regions were analysed (cervical, dorsal and lumbar spinal cord) and $\mathrm{p}^{75-N G r R}$ was found in all of them in correspondence to the primitive sympathetic chain. Anatomical landmarks such as vertebral bodies were used for dissecting sympathetic ganglia (Fig. 1). $\mathrm{p}^{\text {75-NGIR }}$ expression was also 


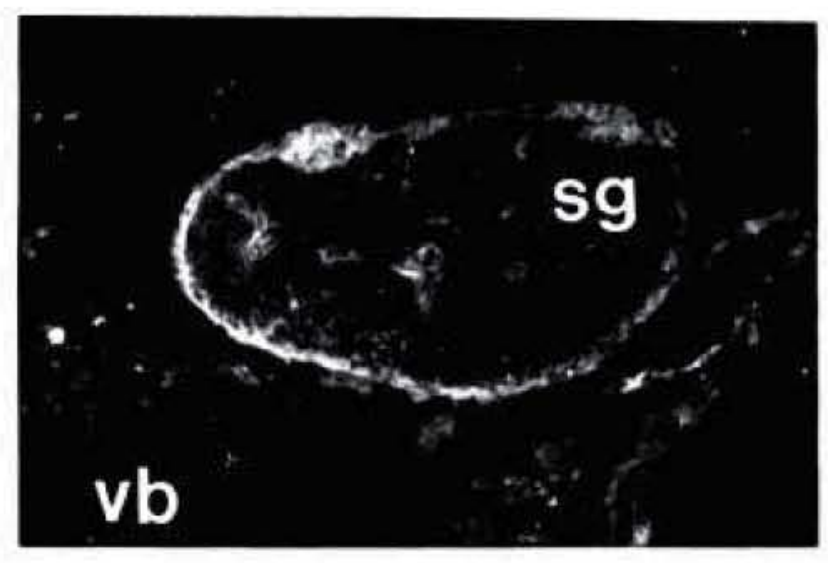

FIG. 1. Micrographs of a sympathetic autonomic chain ganglion (sg) at PC week 8.5 showing immunofluorescence staining for $p^{\text {ss NGF }}$. Anatomical landmarks (vertebral body, vb) were used to localize the sympathetic chain before dissection. Magnification: $\times 70$.

found in the dorsal root ganglia and in the grey matter of the ventral spinal cord (data not shown). Dissociated sympathetic cells were obtained from PC weeks 6.5 to 11.4. In the presence of DMEM/F12 with defined supplements and EGF, floating spheres of proliferating cells were easily identified by contrast microscopy after 8-10 days in vitro, regardless of gestational age (Fig. 2). Second passage spheres were used for cell dispersion. Dissociated EGF-dependent progenitor cells were plated in the presence of an attachment factor, poly-L-lysine. One hour after plating, progenitor cells were attached to the substrate. TH immunoreactivity was present soon after attachment (1-2 h; Fig. 3). Approximately 500 viable progenitor cells (clonal lines) were monitored in both NGF-treated and untreated control cultures. At 1 day in vitro, all viable cells (phase-bright, regular membrane, no granular deposits) were classified in two different cell types: flat, non-neuronal protoplasmic cells and cells with a phase-bright cell body and neuronal-like processes (Fig. 4A, B).

In all the progenitor clones, $\mathrm{TH}$ immunoreactivity was present in all of the sympathetic phase-bright neuronal-like cells. No TH immunoreactivity was

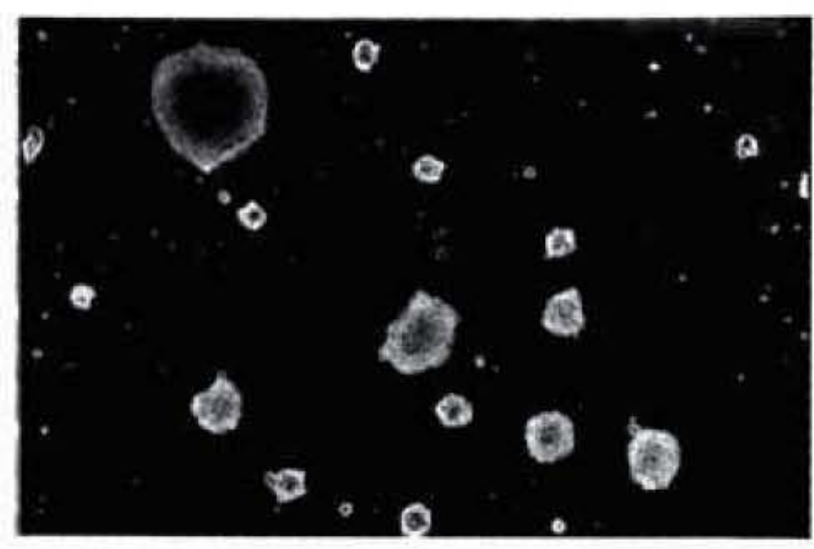

FIG. 2. Second passage floating clusters (spheres) of hrEGF-dependent progenitor cells after 8-10 days in vitro. Magnification: $\times 55$.

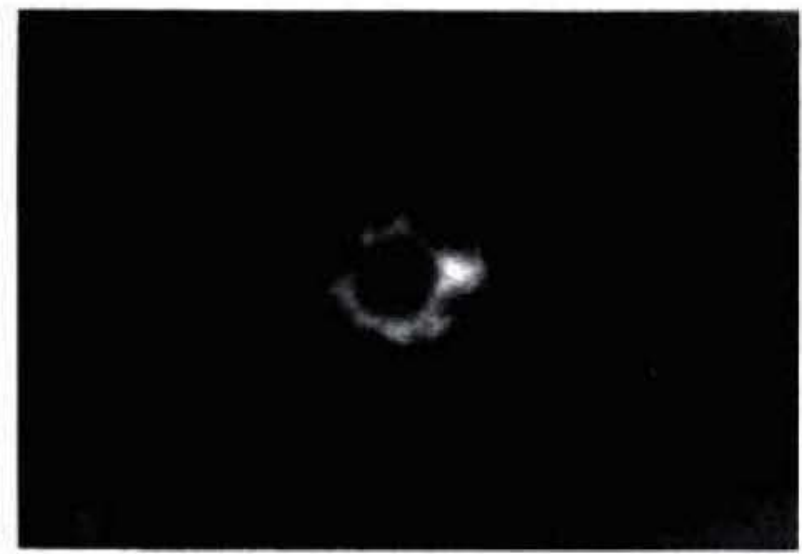

FIG. 3. TH immunoreactivity of hrEGF-dependent progenitor cells $2 \mathrm{~h}$ after attachment after sphere dispersion. Magnification: $\times 275$.

observed in flat, protoplasmic, presumably glia, cells. Furthermore these cells tended to proliferate. Each clonal line $(500 \times 2$ progenitors $)$ we monitored gave rise to both cell phenotypes that tended to grow in close cellular interaction in $57 \pm 7 \%$ s.d. of the clones. At 6 days in vitro after sphere dispersion, the percentage of surviving neuronal cells was $37 \pm 8 \%$ in the controls and $89 \pm 4 \%$ in the NGF-treated cultures (Fig. 5A). The number of surviving neurones at 12 days in vitro was further reduced in untreated $(22 \pm 3 \%)$ compared
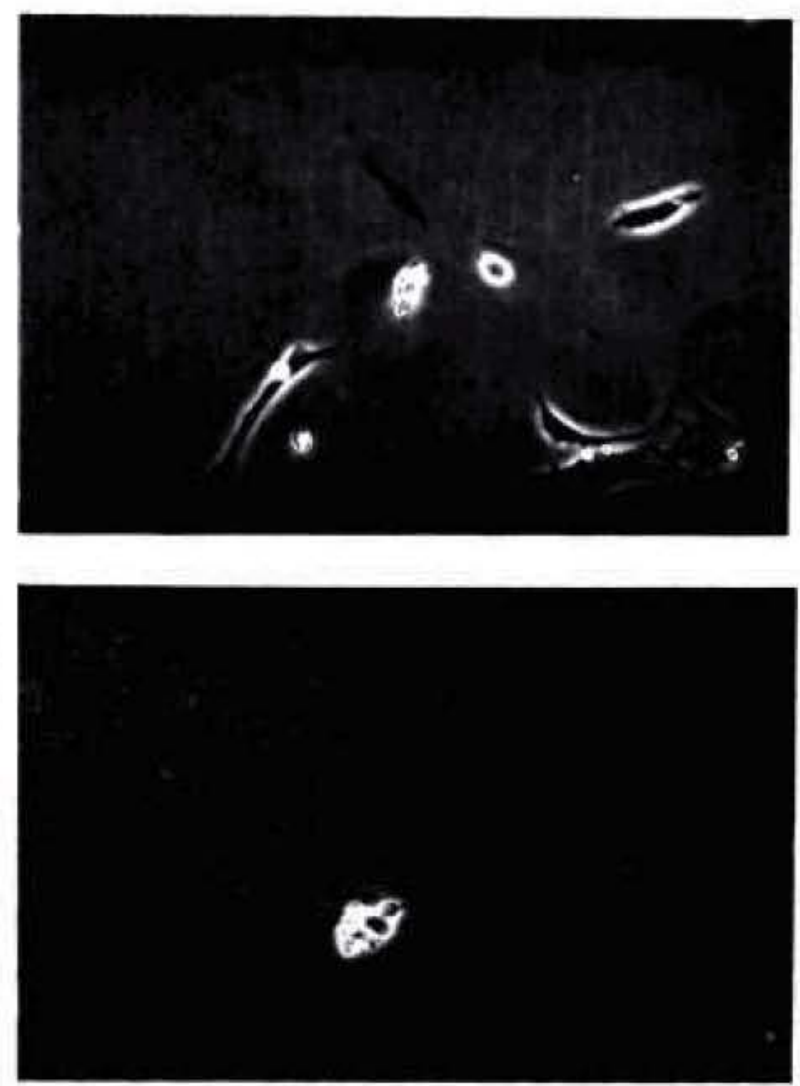

FIG. 4. Effect of NGF on neurite outgrowth: control (A) and NGF ( $30 \mathrm{ng}$ $\mathrm{ml}^{-1}$ (B) treated cells after 6 days in vitro after sphere dispersion. In the control (A), a neuronal-like cells (arrow) without neurite outgrowth is shown. Flat non-neuronal protoplasmic cells were derived from the common EGF-dependent progenitor. Magnification: $\times 110$. 
with NGF-treated cultures ( $69 \pm 4 \%$ ). An average of $67 \pm 8 \%$ cells showed extensive neurite outgrowth after NGF treatment compared with the $8 \pm 3 \%$ of the controls (Figs 4B, 5B). Neurites of the NGF-treated neurones tend to fasciculate and $\mathrm{TH}$ immunoreactivity was demonstrated both in the soma and along the cell processes (Fig. 6A, B).

\section{Discussion}

This study demonstrates that it is possible to isolate, after a few days in vitro, an EGF-dependent sympa-
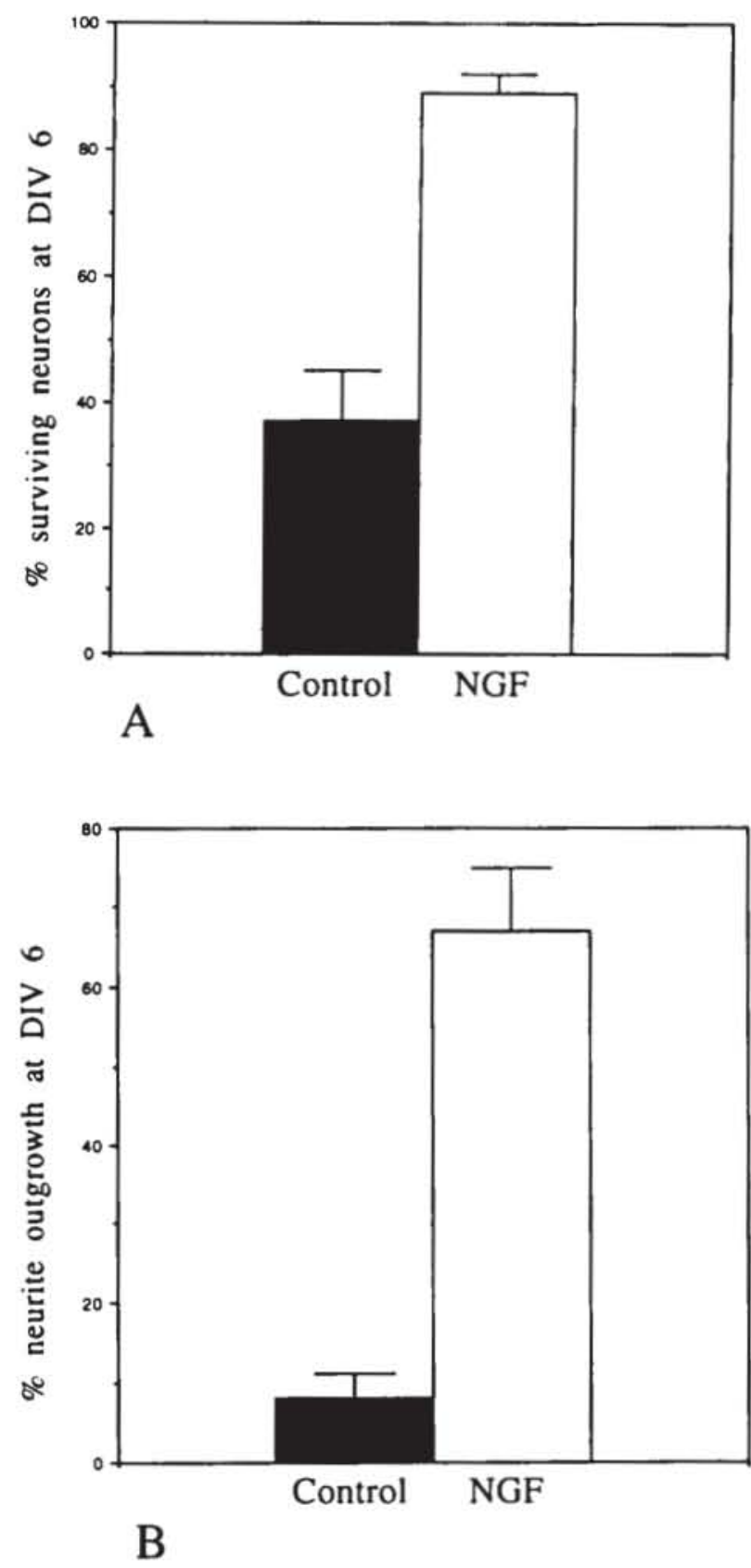

FIG. 5. (A) Surviving neurones after 6 days in vitro (after sphere dispersion): NGF treatment compared with controls. (B) Effects of NGF on neurite outgrowth (more than one cell diameter in length) evaluated at 6 days in vitro after sphere dispersion. thetic progenitor cell from human embryos, which can potentially differentiate into at least two different cell phenotypes in the presence of attachment factor(s). The neuronal-like cells we obtained from the EGFdependent progenitor cell were already committed (early immunoreactivity for $\mathrm{TH}$ ) and promptly responded to NGF in vitro with both neurite extension and increased survival.

At the gestational age we considered, the SA system already migrated to the adrenal gland, originating chromaffin cells. ${ }^{17}$ On the other hand, the EGFdependent progenitor cell does not represent a late stage in neural crest cell differentiation because it retains the ability to generate other neural crest derivatives such as non-neuronal cells. ${ }^{10}$ However, its behaviour is different from that already reported for SA progenitors both from embryonic adrenal glands that were initially unresponsive to NGF,' and from the SA progenitor cell line MAH ( $\mathrm{v}$-myc-infected, adrenal derived-HNK-1- positive cells) that failed to respond to NGF. ${ }^{9}$

Different molecules, including basic fibroblast growth factor (FGF), interleukin-6, IGF-1 and VIP, have been reported to induce initial neuronal differentiation of SA progenitors. ${ }^{18-20}$ Furthermore, FGF and neurotrophin-3 were recently reported to induce NGF responsiveness of SA progenitors after induction of the $\mathrm{p}^{140}$ trk receptor expression. ${ }^{21,22}$ Our results suggest that
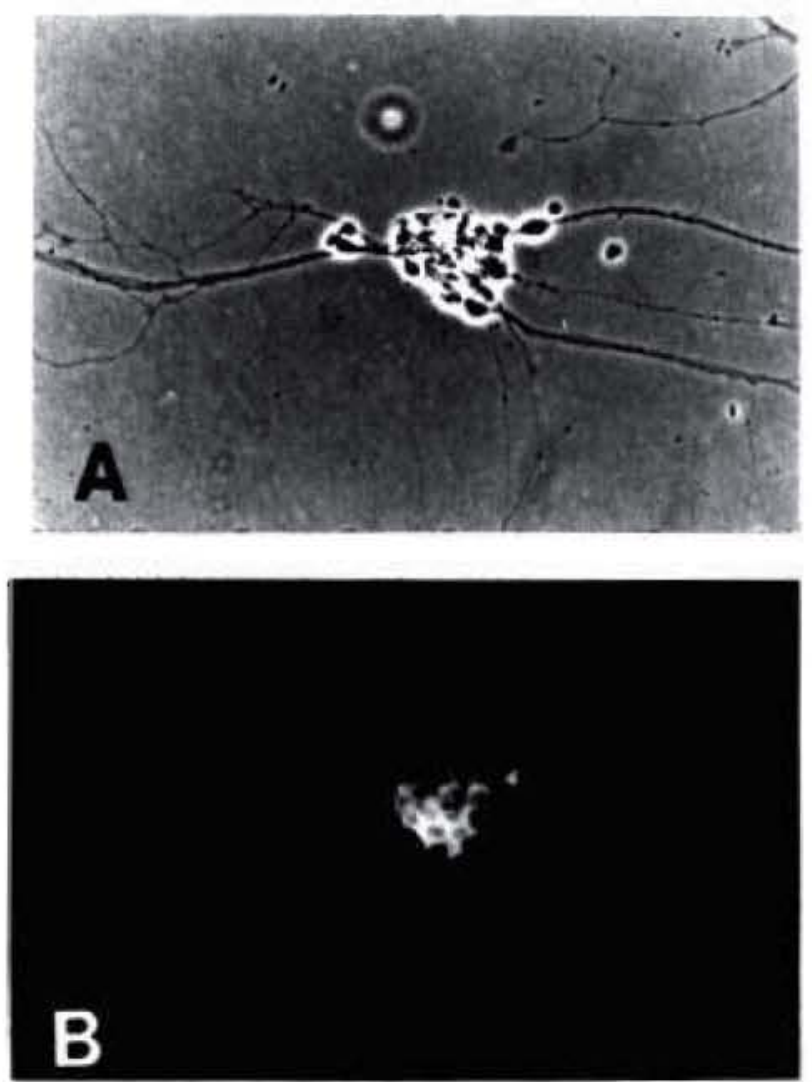

FIG. 6. TH immunoreactivity of NGF stimulated sympathetic neuronal cells at 6 days in vitro after sphere dispersion. (A) phase contrast; (B) TH staining. Magnification: × 140. 
pretreatment with EGF may be one of the factors responsible for the induction of early NGF sensitivity in human sympathetic progenitors, after quantitative modulation of signal transduction through growth factor receptors.

The repertoire of neurotransmitter fates available to the EGF-dependent SA progenitor cell seems to be restricted to the catecholaminergic type, unlike that reported for other SA progenitors such as MAH cells, that have serotonergic as well as cholinergic and catecholaminergic potentials., ${ }^{43}$ Dopamine- $\beta$-hydroxylase (DBH) was demonstrated in the THimmunoreactive cells after double staining (data not shown). Recent studies on the promoter region of the DBH gene mapped the location of DNA sequences necessary for the transcriptional regulation of the DBH gene. ${ }^{24}$ This information appears relevant to produce engineered dopaminergic sympathetic neurones. These cells may be used for brain grafting in the treatment of neurodegenerative diseases characterized by selective impairment of the dopaminergic system, such as Parkinson's disease.

\section{Conclusions}

This report shows that EGF can be used to selectively induce the proliferation of multipotent progenitor cells from the human embryonic sympathetic chain. These cells can differentiate into NGF-responding neuronal cells. The reported method may be used to obtain a large number of catecholaminergic human cells in order to better define the effects of genetic and epigenetic influences on the SA cell fate definition.

\section{References}

1. Landis SC and Patterson PH. Trends Neurosci 4, 172-175 (1981).

1. Landis SC and Patterson PH. Trends Neurosci 4,

2. Patterson PH. Annu Rev Neurosci 1, 1-17 (1978).

4. Doupe A.J, Landis SC and Patterson PH. J Neurosci 5, 2119-2142 (1985).

4. Doupe AJ, Landis SC and Patterson PH. J Neurosci 5, 21 19-2142 (1985).

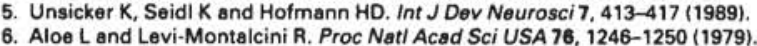

6. Aloe L and Levi-Montalcini R. Proc Natl Acad Sci USA
7. Seidl K and Unsicker K. Dev Biol 136, 481-490 (1989).

8. Unsicker K. Drisch B, Otten J, et al. Proc Natt Acad Sci USA 75, 3498-3502 (1978).

9. Birren SJ and Anderson DJ. Neuron 4, 189-201 (1990)

10. Stemple DL and Anderson DJ. Cell 71, 973-985 (1992).

11. Reynolds BA and Weiss S. Science 255, 1707-1712 (1992).

12. Silani V, Pizzuti A, Strada O ot al, Brain Res 454, 383-386 (1988).

13. O'Rahilly $R$ and Muller F. Carnegie Institution of Washington, Publication 637 (1987).

14. Drumm JF and O'Rahilly R. Am J Anat 148, 550-560 (1977).

15. Robinson HP. Gestational age determination: first trimester. In: Chervenak FA Isaacson GC and Campbell S, eds. Ultrasound in Obstetrics and Gynecology. Isaacson GC and Campbell S, eds. Ultrasound in Obsto

16. Boston: Little, Brown and Company, 1993: 295-304. length measurements. Br J Obstet Gynaecol 82, 702-710 (1975).

17. Silani V, Pezzoli G, Motti E et al. Characterization of purified populations of human fetal chromaffin cells: considerations for grafting in parkinsonian patients. In: Gash DM and Sladek JR Jr, eds. Transplantation into the Mam malian CNS. Amsterdam: Elsevier 1988: 551-557.

18. Rydel RE and Greene LA. Neuroscience 7, 3639-3653 (1987),

19. Togari A, Dickens G, Kuzuka H et al. J Neurosci 5, 307-316 (1985).

20. Rohrer H. Eur J Neurosci 2, 1005-1015 (1990).

21. Verdi JM, Birren SJ, Ibànez CF et al. Neuron 12, 733-745 (1994).

22. Birren SJ, Verdi JM and Anderson DJ. Third Altschul Symposium Abst 22 (1994).

23. Vandenbergh DJ, Mori N, Anderson DJ. Dev Biol 148, 10-22 (1991),

24. Hoyle GW, Mercer EH, Paimiter RD et al. J Neurosci 14, 2455-2463 (1994).

ACKNOWLEDGEMENTS: This research was supported in part by the 'Associazione Amici Centro Dino Ferrari' for Neuromuscular and Neurodegenerative Disease of the University of Milan Medical School and the NIH funded Indiana based Human Fetal Tissue Bank.

Received 15 July 1994; accepted 7 August 1994 